\title{
Health in Iran; 40 Years After the Islamic Revolution
}

\author{
Kamran Bagheri Lankarani (ii) ${ }^{1, *}$ \\ ${ }^{1}$ Health Policy Research Center, Institute of Health, Shiraz University of Medical Sciences, Shiraz, Iran \\ "Corresponding author: Health Policy Research Center, Institute of Health, Shiraz University of Medical Sciences, Shiraz, Iran. Email: lankaran@sums.ac.ir
}

Received 2019 January 20; Accepted 2019 January 20.

\begin{abstract}
Islamic Republic of Iran (IRI) was established 40 years ago. On the 40th anniversary of this new model of the pious practice of democracy that has been involved in major contentions throughout these four decades from war to coup and sanctions, it would be of interest to know the trends in health indicators in Iran. The progress in many aspects including life expectancy and maternal and child health, as well as the provision of sophisticated health services, is tremendous while there are still challenges in combatting non-communicable diseases and financial aspects of the health system.
\end{abstract}

Keywords: Iran, Health, Life Expectancy, Equity, Family Physician, Pharmaceutical Industry, Maternal Mortality

\section{Background}

Health is one of the most important needs of all communities. Knowledge, faith, and values would affect the importance of this issue in the overall agenda of the governments and the way this subject would be approached; but universally, all ruling administrations should be responsible for this important and essential issue of the nations.

Islamic Republic of Iran (IRI) was established 40 years ago after a long period of autocracy in Iran through a revolution mainly orchestrated by religious and poor sectors of the population. In this regard, the newly established government had to focus on closing the gap between poor and wealthier sectors and between rural and urban communities in all aspects, especially health, in concordance with Islamic values.

Now, 40 years after this historical event, one can have an overview of what has been done and what still needs to be done for healthier Iran. This not only is a performance overview for IRI, but also is of utmost importance for other developing countries. Many of these countries are relying on external aids to tackle their needs. The example of IRI as a government that experiences years of sanction by superpowers, especially the United States of America, and at least $25 \%$ of its era being influenced directly by the imposed war, and $25 \%$ more by unsuccessful coupes and planned terrorist attacks aiming at changing the government could be a model for self-reliance and resiliency for other nations.

\section{Methods}

This is a narrative review of the relevant publication and official reports on some of the main health indicators to show the changing trends in the past forty years of Iran.

\section{Results and Discussion}

Major indicators of health including life expectancy (LE), maternal death, and under-five mortality reveal a great improvement. LE at birth increased from below 55 years before 1979 to 75.47 years (75.38 to 75.55 ) for males and 79.36 years (79.28 to 79.46) for females in 2017 (1). Iran is one of the few countries that have gained more than 35 years of LE for both women and men since 1950 and the values are now much higher than the world average (1). Maternal mortality decreased from 237 to 19 per 100,000 and underfive mortality from more than 55 to less than 15 per 100 during the same period.

The establishment of the Iranian model of primary health care (PHC) occurred during the war. A network of health houses and health centers managed by local health workers called Behvarz was launched just in the middle of the Iraq-Iran war (2). This and other health system activities including the expansion of immunization programs, vertical and horizontal programs for contending diarrheal and respiratory tract infections, along with expanding the capacity of universities for training more 
physicians, nurses, and midwives and other needed medical and paramedical staff, all had major impacts in attaining these successes.

The immunization coverage of children before 1979 was just $30 \%$ and it is now more than $95 \%$. As a result, the number of preventable diseases decreased tremendously over the past four decades. Neonatal tetanus, as an example of the success of vaccination programs, was reduced from more than 10,0000 per year to zero. Another important achievement is about poliomyelitis. Iran has been polio-free since 20 years ago. This is not unique to Iran but the importance of this achievement would be further recognized knowing that there are only two countries with ongoing polio epidemics worldwide, both of which are the eastern neighbors of Iran.

The development of pharmaceutical industries in Iran in 1979 was salient. Now, more than $96 \%$ of the quantity and $70 \%$ of the value of drugs are domestically produced. This is of utmost importance when one considers that before 1979 , there were a few native formulations of drugs and most of the pharmaceutical companies at the time only packaged the imported drugs. Iran is now one of the major producers of high tech drugs including biologics in Asia.

Despite the importance of these health system activities, one cannot ignore the importance of the development agenda in promoting the health of the nation. The improvement of health indicators in Iran not only is due to better access to health care but also can be attributed to indicators of development such as net attendance of girls in secondary schools, literacy rate of both men and women, access to sanitary water, and better transportation, among others $(2,3)$. The literacy rate in Iran increased from $40 \%$ in 1979 to more than $90 \%$ in 2017 . This contributed very much to better health indicators of the nation. For instance, it was shown that the effect of the mothers' education on reducing inequality of neonatal mortality was more important than the effects of all other factors (4).

Iran could attain high-quality care with the latest technologies in many fields. Cardiac surgery, once a common cause of referral of patients aboard, now is widely available in the country (2). Organ transplantation including liver has been available in Iran since more than 25 years ago (5, 6 ). Assisted reproduction started in Iran during the war and now, Iran is one of the world leaders in service provision in this field.

Despite all of these signs of progress, there are still many challenges. The Iranian model of PHC has focused on maternal and child mortality, and communicable dis- eases. As seen, it worked well in this regard but it was not renewed for the dynamic transformation of the diseases and health threats. Currently, non-communicable diseases (NCDs) contribute to more than $80 \%$ of all deaths in Iran. However, it is still efficacious in the management of NCDs. As an example, it was shown that those under coverage of rural health centers better controlled their blood sugar compared with the urban citizen not attending health services (7). Although, in recent years, there have been efforts to provide access to PHC in cities, especially in underdeveloped slums, it is still far from real coverage and access.

The problem of road traffic accidents has been growing until mid-twenties resulting in a high death toll of near 30000 per year. A national multisectoral program with collaboration between the Police, Ministry of Health, Ministry of Road and Housing, Iranian Red Crescent Society, Iranian insurance companies, and several other public agencies was launched in 2006, which resulted in death reduction to 17000 in 2012. Since then, the death toll has been almost stable at this rate despite the rise in the number of vehicles from 12 million to more than 24 million (8). The driving under influence of alcohol and drugs has been on the rise, which may have contributed to the failure of further reduction in the burden of road traffic accidents (9). There seems to be a great need for more innovative and socially acceptable interventions to further reduce the number of deaths and injuries.

The transmission pattern of Human immune deficiency virus (HIV) has changed in Iran and now, more sexually transmitted cases are recognized (10).

The migration of the human resource of the health system is becoming a growing problem and there is a need for novel policies to retain young scientists (11). A new program to support knowledge-based companies and foundations has recently been launched for this purpose.

Universal health coverage with financial protection considering the high costs of health services and limited resources is a major concern in Iran as in almost all parts of the world. There has been legislation in the parliament to expand the referral system based on family physician but it is not still a reality (12).

Equity was a highly considered agenda in all programs including health after 1979. The Gini index has been decremented; but, the situation is not still ideal and the latest figure indicates the difference between the costs in the poorest and the wealthier decile is still high and there are inter and intra-provincial differences in health indicators, which are not acceptable. As an example, while the LE of women increased in all provinces, there is a difference of 
up to 8.3 years between provinces in Iran (13).

Despite these and other challenges, based on the achievements in these four decades and the young persuasive new generation, one can predict better health for Iranians in the next decade though increasing sanctions, which is now even in the scientific fields (14), could counteract if not approached judiciously.

\section{Footnotes}

Conflict of Interests: KBL was the Minister of Health and Medical Education of Iran from September 2005 to September 2009.

Funding/Support: None declared.

\section{References}

1. GBD 2017 Mortality Collaborators. Global, regional, and national age-sex-specific mortality and life expectancy, 1950-2017: A systematic analysis for the Global Burden of Disease Study 2017 Lancet. 2018;392(10159):1684-735. doi: 10.1016/S0140-6736(18)31891-9. [PubMed: 30496102]. [PubMed Central: PMC6227504].

2. Bagheri Lankarani K, Alavian SM, Peymani P. Health in the Islamic Republic of Iran, challenges and progresses. Med J Islam Repub Iran 2013;27(1):42-9. [PubMed: 23479501]. [PubMed Central: PMC3592943].

3. Kamiabi F, Torkestani F, Abedini M, Haji-Maghsoudi S, Rastegari A, Hejazi S, et al. [Analysis of the maternal mortality in Iran, 2007-2012]. J Kerman Univ Med Sci. 2015;22(6):650-68. Persian.

4. Amini Rarani M, Rashidian A, Khosravi A, Arab M, Abbasian E, Khedmati Morasae E. Changes in socio-economic inequality in neonatal mortality in iran between 1995-2000 and 2005-2010: An oaxaca decomposition analysis. Int J Health Policy Manag. 2016;6(4):219-8. doi: 10.15171/ijhpm.2016.127. [PubMed: 28812805]. [PubMed Central: PMC5384984].
5. Bagheri Lankarani K, Malek Hosseini SA. The situation of liver transplantation programs in Iran. Middle East J Dig Dis. 2018;10(3):194-5. doi: 10.15171/mejdd.2018.111. [PubMed: 30186585]. [PubMed Central: PMC6119831 work].

6. Malek-Hosseini SA, Jafarian A, Nikeghbalian S, Poustchi H, Lankarani $\mathrm{KB}$, Nasiri Toosi M, et al. Liver transplantation status in Iran: A multicenter report on the main transplant indicators and survival rates. Arch Iran Med. 2018;21(7):275-82. [PubMed: 30041524].

7. Farzadfar F, Murray CJ, Gakidou E, Bossert T, Namdaritabar H, Alikhani S, et al. Effectiveness of diabetes and hypertension management by rural primary health-care workers (Behvarz workers) in Iran: A nationally representative observational study. Lancet. 2012;379(9810):47-54. doi: 10.1016/S0140-6736(11)61349-4. [PubMed: 22169105].

8. Bagheri Lankarani K, Sarikhani Y, Heydari ST, Joulaie H, Maharlouei $\mathrm{N}$, Peimani $\mathrm{P}$, et al. Traffic accidents in Iran, a decade of progress but still challenges ahead. Med J Islam Repub Iran. 2014;28:96. [PubMed: 25664297]. [PubMed Central: PMC4301220].

9. Bagheri Lankarani K, Afshari R. Alcohol consumption in Iran. Lancet. 2014;384(9958):1927-8. doi: 10.1016/S0140-6736(14)62279-0. [PubMed: 25435451].

10. Joulaei H, Bagheri Lankarani K, Kazerooni PA, Marzban M. Number of HIV-infected cases in Iran: True or just an iceberg. Indian J Sex Transm Dis AIDS. 2017;38(2):157-62. doi: 10.4103/2589-0557.216984. [PubMed: 30148270]. [PubMed Central: PMC6085928].

11. Bagheri Lankarani K. A closer look at Iranian migration to the United States. Arch Iran Med. 2015;18(3):205. [PubMed: 25939141].

12. Bagheri Lankarani K, Alavian SM, Haghdoost AA. Family physicians in Iran: Success despite challenges. Lancet. 2010;376(9752):1540-1. doi: 10.1016/S0140-6736(10)62029-6. [PubMed: 21056761].

13. Joulaei H, Maharlouei N, Bagheri Lankarani K, Razzaghi A, Akbari M. Narrative review of women's health in Iran: Challenges and successes. Int J Equity Health. 2016;15:25. doi: 10.1186/s12939-016-0316-x. [PubMed: 26880036]. [PubMed Central: PMC4754925].

14. Bagheri Lankarani K, Haghdoost A, Smith P. Embargo on publication of scientific papers by Iranian authors. Lancet. 2012;380(9842):648-9. doi: 10.1016/S0140-6736(12)61369-5. [PubMed: 22901883]. 